\title{
MRI-findings in idiopathic intracranial hypertension (Pseudotumor cerebri)
}

\section{MRT-Befunde bei der idiopathischen intrakraniellen Hypertension (Pseudotumor cerebri)}

Authors

Julia Juhász, Johannes Hensler@, Olav Jansen

Affiliation

Department of Radiology and Neuroradiology, University

Hospital Schleswig-Holstein - Campus Kiel, Germany

Key words

pseudotumor cerebri, idiopathic intracranial hypertension, secondary intracranial hypertension, MRI, MR-venography

received 31.10 .2020

accepted 03.03.2021

published online 12.05 .2021

Bibliography

Fortschr Röntgenstr 2021; 193: 1269-1276

DOI $10.1055 / a-1447-0264$

ISSN $1438-9029$

(C) 2021. Thieme. All rights reserved.

Georg Thieme Verlag KG, Rüdigerstraße 14,

70469 Stuttgart, Germany

Correspondence

Dr. Julia Juhász

Radiologie und Neuroradiologie, Universitätsklinikum

Schleswig-Holstein, Arnold-Heller-Str. 3, 24105 Kiel, Germany

Tel.: +49/4 31/50016501

julia.juhasz@uksh.de

\section{ABSTRACT}

Background Pseudotumor cerebri, also known as idiopathic intracranial hypertension, is a disorder of increased intracranial pressure of unknown etiology. Main symptom is headache which has a characteristic similar to other headache diseases, therefore the idiopathic intracranial hypertension often remains undetected. The incidence is $1 / 100000$ with the number of unreported cases being much higher. This article highlights the essential role of MRI in the differential diagnosis.

Methods A literature search was carried out on idiopathic intracranial hypertension and Pseudotumor cerebri in English and German. Original and Review articles as well as case reports were taken into account. Since the main focus of the article is MRI diagnostics, some images were selected to illustrate the characteristic MRI morphological features.

Results and Conclusion The diagnosis of idiopathic intracranial hypertension is based on an exclusion procedure. Most common syndromes are headache, transient visual obscura-

tions, pulsatile tinnitus and nausea. In the presence of an underlying cause for the increased intracranial pressure one speaks of a secondary intracranial hypertension. The diagnostics include a detailed medical history, neurological and ophthalmic examination, lumbar puncture, and neuroradiological imaging procedures. MRI, in particular, has become increasingly important in recent years, since signs for changes in cerebrospinal fluid pressure are now detectable and well-defined. The therapeutic approaches are symptom-oriented and aim to lower the pressure. With a precise diagnosis and timely start of therapy, idiopathic intracranial hypertension has a good prognosis, especially with regard to the preservation of eyesight.

Key Points:

- The idiopathic intracranial hypertension is an important differential diagnosis for unspecific headache and impaired vision

- Overweight women in childbearing age are particularly affected

- The most important component in diagnostics is MRI

\section{Citation Format}

- Juhász J, Hensler J, Jansen O. MRT-Befunde bei der idiopathischen intrakraniellen Hypertension (Pseudotumor cerebri). Fortschr Röntgenstr 2021; 193: 1269-1276

\section{ZUSAMMENFASSUNG}

Hintergrund Der Pseudotumor cerebri, auch idiopathische intrakranielle Hypertension genannt, ist eine Erkrankung mit erhöhtem Liquordruck unklarer Genese. Leitsymptom sind Kopfschmerzen, dessen Charakteristiken anderen Kopfschmerzerkrankungen ähneln, weshalb die idiopathische intrakranielle Hypertension oft unerkannt bleibt. Die Inzidenz wird mit 1/100 000 angegeben, wobei die Dunkelziffer wesentlich höher liegt. Dieser Artikel weist auf die essenzielle Rolle der MRT-Bildgebung in der Differenzialdiagnostik hin. Methode Es wurde eine Literaturrecherche zu dem Syndrom IIH und Pseudotumor cerebri in englischer und deutscher Sprache durchgeführt. Berücksichtigt wurden sowohl Original- und Übersichtsarbeiten als auch Fallbeispiele. Da der Schwerpunkt des Artikels die MRT-Diagnostik ist, wurde eine Bilderauswahl getroffen, um die charakteristischen MR-morphologischen Merkmale zu veranschaulichen. 
Ergebnisse und Schlussfolgerung Die Diagnose der idiopathischen intrakraniellen Hypertension beruht auf einem Ausschlussverfahren. Die typischen klinischen Symptome sind Kopfschmerzen, Sehstörung, pulsatiler Tinnitus und Übelkeit. Findet man eine zugrunde liegende Ursache für den erhöhten intrakraniellen Druck, spricht man von einer sekundären intrakraniellen Hypertension. Die Diagnostik beinhaltet eine ausführliche Anamnese, neurologische und ophthalmologische Untersuchungen, Lumbalpunktion und neuroradiolo- gische bildgebende Verfahren. Insbesondere die MRT hat in den letzten Jahren an Bedeutung gewonnen, da mittlerweile gut erkennbare Zeichen einer Liquordruckänderung definiert sind. Die Therapieansätze sind symptomorientiert und haben das Ziel der Drucksenkung. Bei genauer Diagnostik und rechtzeitigem Therapiebeginn hat die idiopathische intrakranielle Hypertension eine gute Prognose, besonders was die Erhaltung der Sehfähigkeit betrifft.

\section{Introduction}

Physiologically, intracranial pressure in healthy adults is 5$15 \mathrm{cmH} 2 \mathrm{O}$. Values above $20-25 \mathrm{cmH} 2 \mathrm{O}$ are considered pathologically increased intracranial pressure (intracranial hypertension) [1]. Elevated CSF pressure can lead to symptoms such as headache, vision disturbance, pulsatile tinnitus and nausea [2]. This syndrome was grouped under the name pseudotumor cerebri (PTC) and described by the German neurologist Max Nonne in 1904. His aim was to differentiate this group of patients from those with increased intracranial brain pressures due to cerebral tumors, as they exhibited the same clinical symptoms [3]. Nowadays, this definition is no longer up-to-date, since several pathologies, pathophysiological changes and drugs are now known to lead to an increase in intracranial pressure. If an underlying cause is found, it is referred to as secondary intracranial hypertension $(\mathrm{SIH})$. If the etiology remains unknown, the disease pattern is called idiopathic intracranial hypertension (IIH), a concept introduced in 1989 by Corbett and Thomson.

$\mathrm{IIH}$ is a complex condition that is not yet fully understood, with an incidence of 0.9/100000 in Western countries [4], although it can be assumed that unreported cases are significantly higher. On the one hand, technical developments in recent years have significantly improved diagnostics; on the other hand, the prevalence of obesity has increased worldwide [5].

Large differences are also observed depending on geographical location; the reason for this is not yet fully understood. It seems that genetic predisposition plays a minor role compared to environmental factors [6], although BMI provides the strongest correlation [7]. This explains the higher incidence of 19/100 000 in overweight women (20\% overweight). IIH can occur at any age, but the largest risk group is overweight women of childbearing age [8]. Depending on the study, the female-to-male incidence ratio varies from $4: 1$ to 15:1 [9]. In children, an incidence of 0.5/100 000 was found without gender and BMI-related differences [10].

\section{Symptomology}

Clinical symptoms are caused by increased intracranial pressure and may vary from individual to individual.

Headaches are the most common, occurring in 68-98\% of cases [4]. Headache characteristics may vary widely, can aggravate under certain circumstances such as coughing, body positioning and exertion, and may also show similarities to migraine and tension headache [11]. The latter is also the reason why IIH can easily be misdiagnosed.

The second most common complaint is vision disturbances, which are described in $72 \%$ of cases, occurring on one or both sides and ranging from reduced visual acuity to blindness [12]. Vision disturbances are mainly caused by papillary edema, which can be detected in $95 \%$ of cases during ophthalmological examinations, thus vision disturbances are a good indicator of increased CSF pressure. The remaining cases are referred to as idiopathic intracranial hypertension without papilledema (IIHWOP) [13, 14].

Pulsatile tinnitus is another common symptom at $60 \%$ [12].

In addition, there are other, non-specific symptoms such as nausea, vomiting and olfactory disorders $[15,16]$.

\section{Pathophysiology}

Although aspects of this disease pattern are increasingly becoming known, the exact pathomechanism has not yet been clarified.

The Monro-Kellie doctrine states that in a rigid system such as the cranium, the three components (brain tissue, blood, cerebrospinal fluid) within it form a constant volume, whereby a change in one component necessarily results in a change in the other two [17].

There are several theories regarding the genesis of $\mathrm{IIH}$. The common characteristic is the increased CSF pressure, but it is questionable whether there is a uniform mechanism at all and not rather several pathophysiological events acting on each other, which culminate in a vicious circle and result in the syndrome.

\section{Cerebral spinal fluid}

CSF is largely produced by the choroid plexus; its production is pressure-independent and relatively constant, but decreases with age. The theory that the increased intracranial pressure is due to an overproduction of cerebrospinal fluid could not be proven [18].

Dysregulation in water transport may play a role in the pathomechanism, as the water channel protein aquaporin-4 is known to be associated with brain edema and, together with aquaporin-1, forms the therapeutic approach to drug therapy. Thus, downregulation of these channels can lead to symptom improvement, whereas glucocorticoids and retinoids upregulate AQP1 channels and cause symptoms to worsen [19].

CSF flows from the ventricles into the subarachnoid space, where it is reabsorbed via arachnoid granulations. The resorption 
rate depends on the pressure gradient between the subarachnoid space and the veins and sinuses. With increased venous pressure, CSF reabsorption is impeded, increasing cerebrospinal and intracranial pressure [20].

There are also additional CSF drainage pathways, such as the lymphatic and g-lymphatic systems [21], which explains why fetuses and children without arachnoid granulations have functioning CSF circulation.

\section{Venous sinus}

We know from invasive studies that intracranial venous pressure is elevated in IIH patients [22]. Whether this is a consequence or cause of increased intracranial pressure is still under discussion today. MR morphological correlates are uni- or bilateral sinus stenoses, which are found in almost all IIH patients [23].

Several publications describe the decrease in sinus stenosis after normalization of CSF pressure, suggesting the primary role of this pressure [24-27].

Other authors have observed that in the vast majority of cases, sinus stenoses persist after CSF pressure relief [28, 29]. Accordingly, sinus stenosis can probably be considered the cause of increased CSF pressure rather than the consequence in some cases.

Current scientific knowledge also widely accepts that sinus stenosis (primary or secondary) plays an important role in increasing intracranial venous and CSF pressure.

Due to the changed pressure gradient between the spinal fluid and veins, CSF resorption is reduced, which maintains or increases the pathological condition [30].

According to another hypothesis, disturbed vascular autoregulation can lead to cerebral hyperemia due to increased intracranial arterial influx even without a relevant venous outflow obstruction, which forms the basis for the increased intracranial pressure [31]. However, this could not be confirmed in a more recent study [32].

\section{Parenchymal edema}

The role of cerebral edema in the development of IIH has not been adequately demonstrated to date [33].

\section{Obesity and sex}

Associations between increased BMI or recent weight gain, female sex, and IIH are statistically proven, but pathophysiological bases are still lacking [34]. Various hormonal aspects are discussed, such as leptin, glucocorticoids, aldosterone or sex hormones [18, 35].

With certain drugs (various hormones, antibiotics, NSAIDs, vitamin A, lithium), increased intracranial pressures have been observed in some cases, although the causal correlation has not been clearly established [36, 37].

\section{Diagnosis}

IIH is a diagnosis of exclusion. The modified Dandy criteria continue to form the basis for diagnosis [15]:

1. Symptoms of intracranial pressure increase (headache, vision disturbance, etc.), papilledema
2. Evidence of elevated cerebrospinal fluid pressure $(>25 \mathrm{cmH} 20$ with lumbar puncture in the supine position)

3. Normal CSF composition

4. Exclusion of differential diagnoses

5. No focal neurological deficit (except unilateral and bilateral abducens palsies)

6. Normal CT or MRI

Technical developments of the last decades, especially in imaging diagnostics, led to the revision of item 6. MRI imaging made it possible to visualize indirect intracranial pressure signs [38, 39].

In addition, the increasing number of publications in recent years has led to expansion of diagnostic criteria. In 2013, the diagnostic criteria were revised and updated, especially for patients with IIHWOP, who often have less elevated CSF pressure than patients with papilledema [14]. In such cases, the diagnosis of IIH should be made on the basis of radiological features in conjunction with other available clinical and diagnostic findings. Thus, the limit of CSF opening pressure between $20-25 \mathrm{cmH} 20$ is also discussed as a diagnostic gray area and considered pathological by some authors from $20 \mathrm{cmH} 20$ onwards [1, 28, 40]. If not all criteria are met, the diagnosis of $\mathrm{IIH}$ is an individual decision [40].

\section{MRI findings}

MRI is now the most important component in the diagnosis of $\mathrm{IIH}$, used not only to rule out causes of increased intracranial pressure, but also to detect subtle changes in the cranium caused by increased pressure. Due to higher sensitivity and lack of radiation exposure, it is clearly superior to computed tomography.

An appropriate standard MRI protocol to rule out secondary intracranial pressure elevation includes:

- Axial DWI (3 mm),

- Axial T2w (3 mm),

- FLAIR (fluid-attenuated inversion recovery, $4 \mathrm{~mm}$ ),

- MR venography, e. g. PCA (venous phase contrast angiography, velocity encoding VENC $15 \mathrm{~cm} / \mathrm{s}$ ) for non-contrast imaging of the venous vessels,

- Coronal STIR (fat-suppressed inversion recovery sequence) of the orbita and sella $(3 \mathrm{~mm})$.

There are now numerous published MR morphologically detectable signs of intracranial pressure elevation that are reliably detected with the MR protocol listed above, although good quality MR venography is of critical importance [41].

Typical pitfalls of venous phase-contrast angiography include Paccioni granulations, which can mimic stenosis. In most cases, these can be identified as such based on their strong T2w hyperintense signal. "Genuine" sinus stenoses do not show high signals in T2w images. In case of ambiguous findings, contrast-enhanced MR angiography in combination with a 3 D T1 data set can also be performed as a supplement.

The most important MRI signs in descending diagnostic weighting are:

1. Uni- or bilateral sinus stenoses ( $\triangleright$ Fig. 1 ),

2. Excavation of the pituitary gland to the "empty sella"

( Fig. 2), 


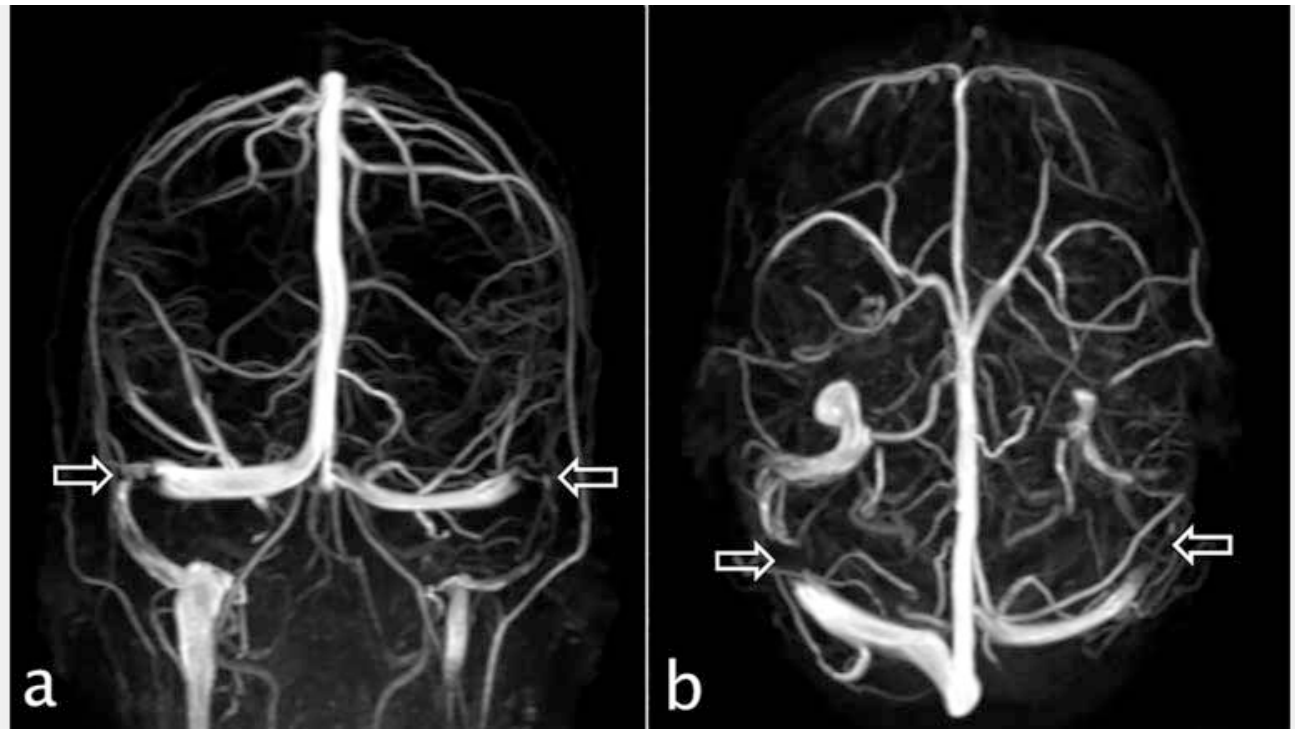

- Fig. 1 Venous PCA shows bilateral sinus stenoses at the junction of the transverse sinus and the sigmoid sinus (arrows), coronal a, axial b.

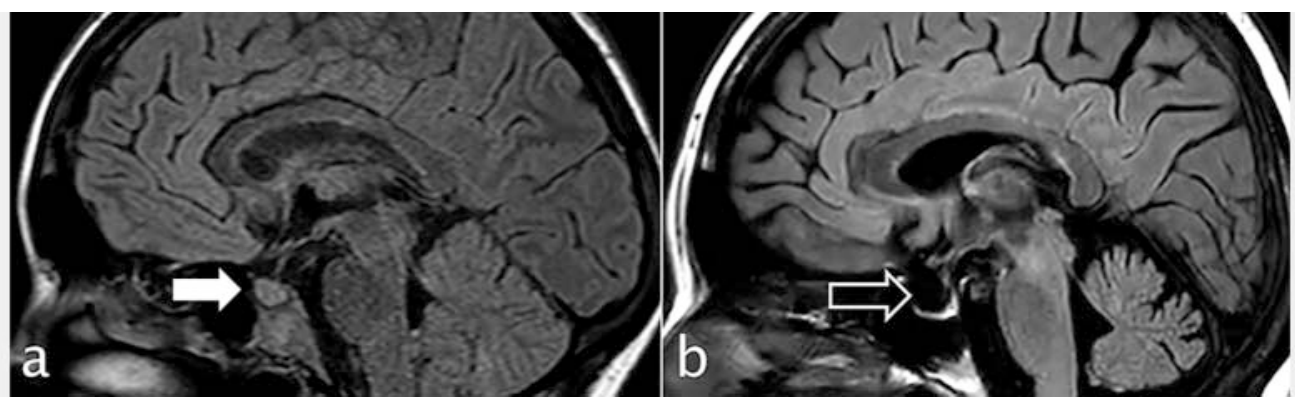

- Fig. 2 Left a a healthy young female patient (filled arrow), right b female patient with increased CSF pressure and excavated pituitary gland (empty arrow) in the sagittal FLAIR sequence.

3. Bilateral dilatation of the optic sheaths ( $\triangleright$ Fig. 3),

4. Flattening of posterior sclera ( $\triangleright$ Fig. 4a),

5. Tortuosity of the optic nerve ( $\triangleright$ Fig. $4 \mathbf{b}$ ),

6. Preliminary enhancement of the optic nerve,

7. Dilatation of the Meckel cavity,

8. Expansion of the superior ophthalmic vein,

9. Dilatation of the foramina of the skull base, such as the foramen ovale [42].

Uni- or bilateral sinus stenoses are found in almost all IIH patients. Bilateral sinus stenoses are especially pathognomonic for this disease [11]. These are found predominantly at the transition from the transverse sinus to the sigmoid sinus ( $\triangleright$ Fig. 1), but also in the course of the transverse sinus and in the distal sigmoid sinus above the confluence of sinuses [43]. The extent of stenosis ranges from mild constriction to flow interruption. In some cases, reversibility of the stenoses is then seen after successful pressure reduction via lumbar puncture [24, 44], in other cases, however, a persistence of the stenoses can be observed, which makes them appear as fixed stenoses [28, 29].

In a healthy state, the pituitary gland has a roundish configuration, especially in younger patients. Under increased CSF pressure, however, it shows flattening or excavation to the point of an “empty” sella ( $>$ Fig. 2). After normalization of CSF pressure, there may be an increase in pituitary height again. The normal values for pituitary height differ between the sexes; in addition, pituitary volume decreases with age, which must be taken into account when assessing this pressure phenomenon [45].

The width of the liquid-filled optic sheaths shows no age-related variance, which is why it is a good marker for intracranial pressure conditions [45]. The optic sheaths are barely detectable when there is negative pressure; they are usually slender, and when the pressure is positive they expand ( $\vee$ Fig. 3). In the latter case, one speaks of an optic sheath hydrops, which can also be visualized sonographically.

Although congestion papillae are not an MRI phenomenon, they are still visible MR morphologically in pronounced cases ( $\triangleright$ Fig. 4a).

Unlike other forms of CSF hypertension (hydrocephalus), the ventricles in IIH are normally wide.

Differential diagnosis includes all diseases that may lead to or be associated with increased intracranial pressure. The clinical work-up includes a detailed neurological examination with laboratory and cerebrospinal fluid diagnostics as well as ophthalmologi- 
cal examinations with special regard to congestion papillae. It should be noted that a pathologically altered CSF status rules out the diagnosis of $\mathrm{IIH}$, but absent congestive papillae does not (IIHWOP).

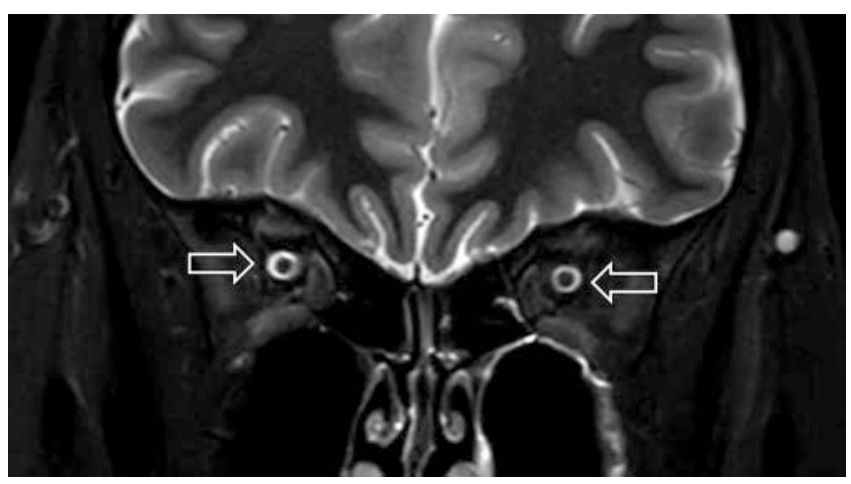

- Fig. 3 Expanded optic sheaths (arrows) in the coronal STIR sequence.
Radiologically relevant differential diagnoses are primarily sinus or venous thromboses ( $>$ Fig.5), intracranial and spinal lesions, various forms of hydrocephalus, vascular malformations (dAVF), meningeosis, meningitis, and encephalitis.

\section{Therapy}

To date, there are no evidence-based treatment guidelines [46]. The therapeutic decision is individual and depends on the severity of the symptoms. The primary goal is to preserve vision and relieve headache symptoms. The desired pressure reduction can be achieved by means of invasive and non-invasive forms of therapy.

Unless acute visual disturbances (loss of visual acuity) force an immediate therapy, treatment follows an escalation strategy:

1. Non-invasive options include medications and weight loss.

The most effective drugs are acetazolamides from the group of carbonic anhydrase inhibitors, which reduce CSF production by up to $57 \%$ [46]. Other medications include the diuretic furosemide and the antiepileptic topiramate $[47,48]$; the latter is

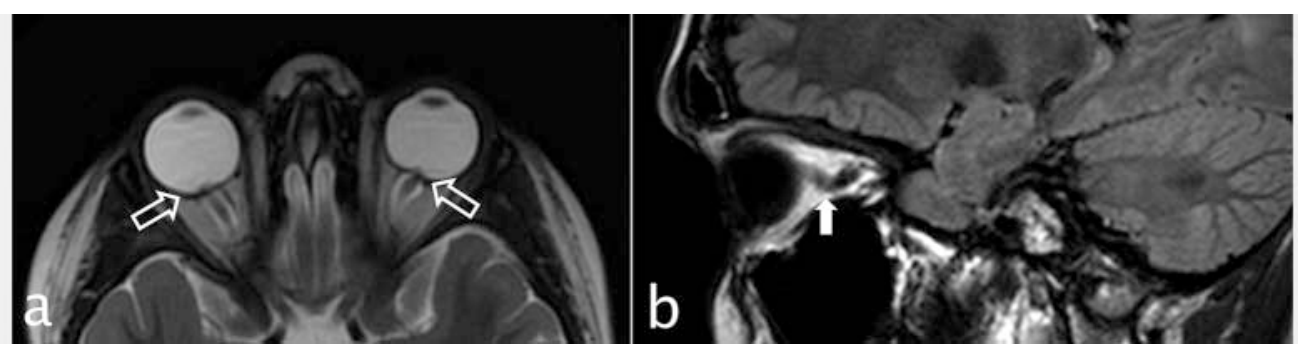

Fig. 4 Congestive papillae and flattening of the posterior sclera (empty arrows) in the axial T2w sequence a and tortuosity of the optic nerve (white arrow) in the sagittal FLAIR image $\mathbf{b}$.
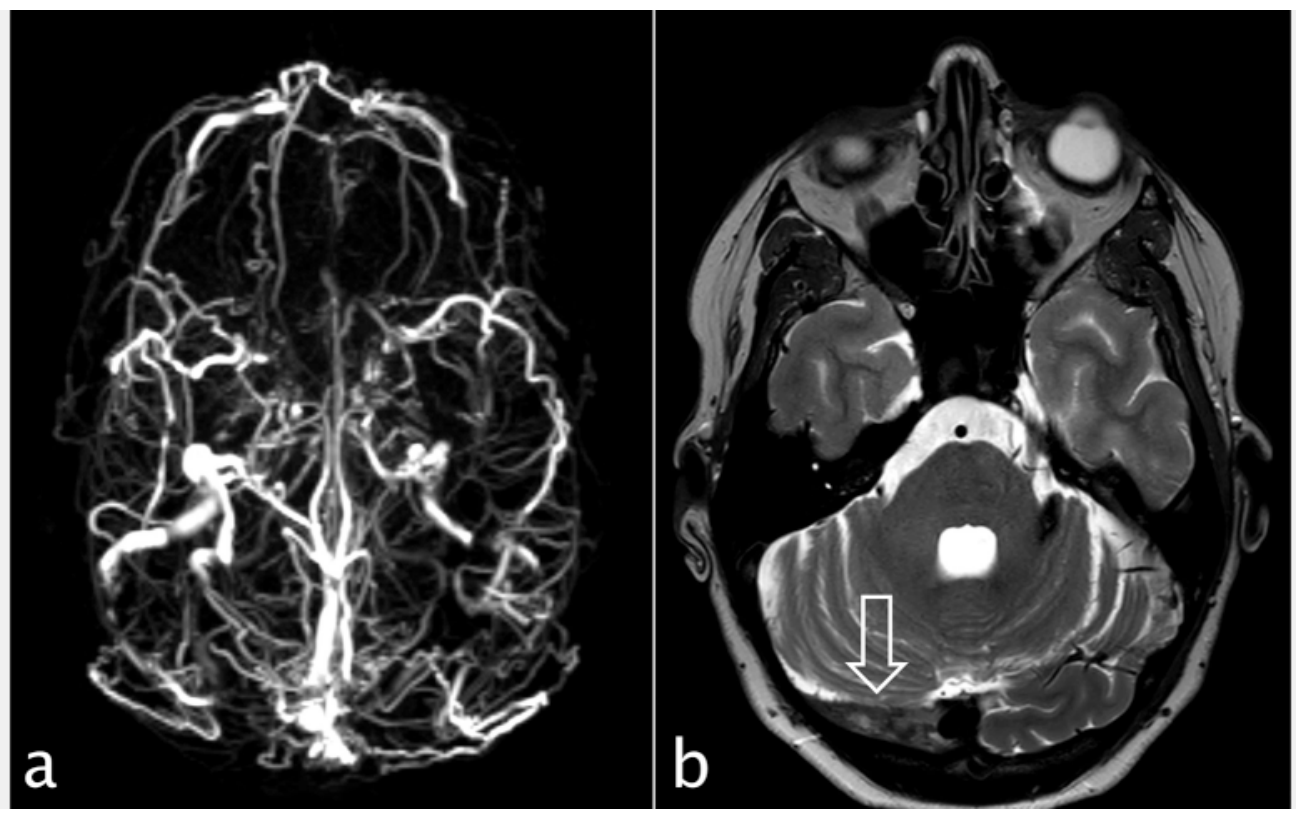

- Fig. 5 Thrombosis of the transverse and sigmoid sinuses on both sides and part of the superior sagittal sinus in the venous PCA a. Correlated to this is the lack of a flow signal in the right transverse sinus (arrow) in the axial T2-weighted sequence $\mathbf{b}$. 


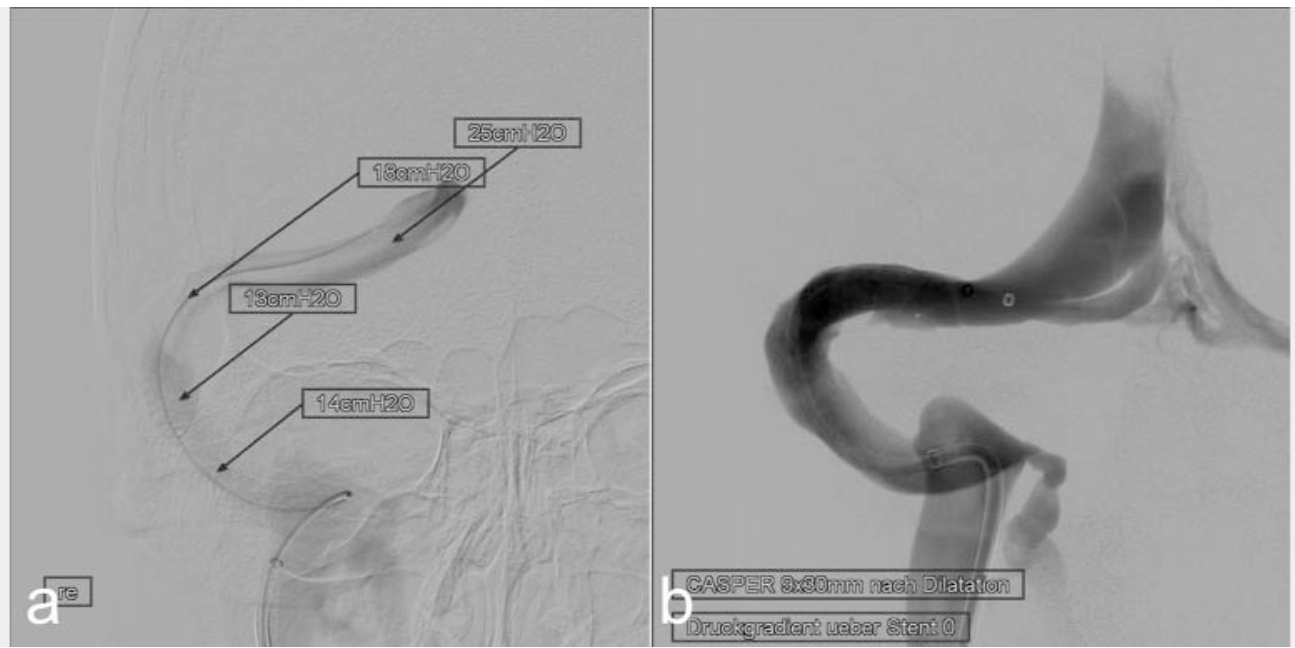

- Fig. 6 Diagnostic angiography of a 21-year-old female IIH patient with bilaterally fixed sinus stenoses as demonstrated by MRI. Digital subtraction angiography shows a pressure gradient of $11 \mathrm{cmH} 20$ a over the sinus stenosis on the right at the transverse-sigmoid junction. After successful stent angioplasty of this stenosis, normalization of the pressure gradient to $0 \mathrm{cmH} 20$ above the stent $\mathbf{b}$.

also used in migraine prophylaxis. Corticosteroids are now no longer recommended in therapy [49].

Numerous studies have shown a positive correlation between BMI and CSF pressure [50]. Congestive papillae in particular react sensitively to weight reduction, their reversibility is a good indicator of successful therapy [51].

2. Invasive methods include lumbar puncture (LP), which is also considered the diagnostic gold standard. Lumbar puncture is used to determine opening pressure, obtain CSF for analysis, and provide therapeutic pressure relief. In a few cases, a single LP is sufficient to produce longer-term clinical improvement [27], but most often the procedure must be repeated several times. On average, approximately $30 \mathrm{ml}$ of CSF is collected.

3. Stent angioplasty of the sinuses: Endovascular therapy has become the first invasive treatment option of choice, especially in specialty centers. For a long time, this was mainly true for MR-morphologically fixed sinus stenoses after lumbar puncture, but is now also valid for non-fixed stenoses. Regardless of the direction of the causality between increased CSF pressure and venous pressure, there is positive interaction between the two components [52]. Implantation of a stent in the stenosis not only reduces the venous but also the CSF pressure, which leads to an improvement in the clinical symptoms [53, 54] ( $\triangleright$ Fig. 6).

4. Other surgical measures to reduce the CSF pressure should be mentioned here, but apart from bariatric approaches, they are becoming more and more of a secondary importance: lumboperitoneal and ventriculoperitoneal shunt [55], optic nerve fenestration [56] as well as bariatric surgery for weight reduction [57].

\section{Summary}

$\mathrm{IIH}$ is an often unrecognized condition and predominantly affects young overweight women. Patients often present to the clinic with nonspecific headaches. Because headaches occur as a concomitant symptom in many diseases, they often go unrecognized although they are much more common than assumed. In these patients, MRI should be performed during the diagnostic workup to exclude secondary causes of headache. Since IIH is associated with increased CSF pressure, it is imperative to know the pressure signs on MRI and choose an appropriate related protocol. In particular, a good MR phlebography technique is of great relevance, since bilateral sinus stenoses are pathognomonic for this pathology.

\section{Conflict of Interest}

The authors declare that they have no conflict of interest.

\section{References}

[1] Bono F, Cristiano D, Mastrandrea C et al. The upper limit of normal CSF opening pressure is related to bilateral transverse sinus stenosis in headache sufferers. Cephalalgia: an international journal of headache 2010; 30: $145-151$

[2] Thurtell M], Bruce BB, Newman NJ et al. An update on idiopathic intracranial hypertension. Reviews in neurological diseases 2010; 7: e56-e68

[3] Rohr A. Pseudotumor cerebri. Neuroradiol Scan 2013; 3: 267-284

[4] Ball AK, Clarke CE. Idiopathic intracranial hypertension. The Lancet Neurology 2006; 5: 433-442

[5] Kilgore KP, Lee MS, Leavitt JA et al. Re-evaluating the Incidence of Idiopathic Intracranial Hypertension in an Era of Increasing Obesity. Ophthalmology 2017; 124: 697-700

[6] Bruce BB, Preechawat P, Newman NJ et al. Racial differences in idiopathic intracranial hypertension. Neurology 2008; 70: 861-867

[7] Alperin N, Ranganathan S, Bagci AM et al. MRI evidence of impaired CSF homeostasis in obesity-associated idiopathic intracranial hypertension. AJNR. American journal of neuroradiology 2013; 34: 29-34

[8] Kosmorsky GS. Idiopathic intracranial hypertension: pseudotumor cerebri. Headache 2014; 54: 389-393 
[9] Skau M, Brennum J, Gjerris F et al. What is new about idiopathic intracranial hypertension? An updated review of mechanism and treatment. Cephalalgia: an international journal of headache 2006; 26: 384-399

[10] Tibussek D, Distelmaier F, von Kries $R$ et al. Pseudotumor cerebri in childhood and adolescence - results of a Germany-wide ESPED-survey. Klinische Padiatrie 2013; 225: 81-85

[11] Bono F, Messina D, Giliberto $C$ et al. Bilateral transverse sinus stenosis predicts IIH without papilledema in patients with migraine. Neurology 2006; 67: 419-423

[12] Wall MGD. Idiopathic intracranial hypertension. A prospective study of 50 patients. Brain 1991; 114: 155-180

[13] Messina D, Bono F, Fera F et al. Empty sella and bilateral transverse sinus stenosis predict raised intracranial pressure in the absence of papilloedema: a preliminary study. Journal of neurology 2006; 253: 674-676

[14] Digre KB, Nakamoto BK, Warner JEA et al. A comparison of idiopathic intracranial hypertension with and without papilledema. Headache 2009; 49: 185-193

[15] Friedman DI, Jacobson DM. Diagnostic criteria for idiopathic intracranial hypertension. Neurology 2002; 59: 1492-1495

[16] Khoo KF, Kunte H. Olfactory dysfunction in patients with idiopathic intracranial hypertension. Neurology 2014; 82: 189

[17] Mokri B. The Monro-Kellie hypothesis: applications in CSF volume depletion. Neurology 2001; 56: 1746-1748

[18] McGeeney BE, Friedman DI. Pseudotumor cerebri pathophysiology. Headache 2014; 54: 445-458

[19] Mollan SP, Ali F, Hassan-Smith G et al. Evolving evidence in adult idiopathic intracranial hypertension: pathophysiology and management. Journal of neurology, neurosurgery, and psychiatry 2016; 87: 982-992

[20] Karahalios DG, Rekate HL, Khayata MH et al. Elevated intracranial venous pressure as a universal mechanism in pseudotumor cerebri of varying etiologies. Neurology 1996; 46: 198-202

[21] Lenck S, Radovanovic I, Nicholson P et al. Idiopathic intracranial hypertension: The veno glymphatic connections. Neurology 2018; 91: 515-522

[22] King JO, Mitchell PJ, Thomson KR et al. Manometry combined with cervical puncture in idiopathic intracranial hypertension. Neurology 2002; 58: $26-30$

[23] Farb RI, Vanek I, Scott JN et al. Idiopathic intracranial hypertension: the prevalence and morphology of sinovenous stenosis. Neurology 2003; 60: 1418-1424

[24] Higgins JNP, Pickard JD. Lateral sinus stenoses in idiopathic intracranial hypertension resolving after CSF diversion. Neurology 2004; 62: 19071908

[25] Buell T], Raper DMS, Pomeraniec I] et al. Transient resolution of venous sinus stenosis after high-volume lumbar puncture in a patient with idiopathic intracranial hypertension. Journal of neurosurgery 2018; 129: 153-156

[26] Rohr A, Dörner L, Stingele R et al. Reversibility of venous sinus obstruction in idiopathic intracranial hypertension. AJNR. American journal of neuroradiology 2007; 28: 656-659

[27] de Simone R, Marano E, Fiorillo C et al. Sudden re-opening of collapsed transverse sinuses and longstanding clinical remission after a single lumbar puncture in a case of idiopathic intracranial hypertension. Pathogenetic implications. Neurological sciences: official journal of the Italian Neurological Society and of the Italian Society of Clinical Neurophysiology 2005; 25: 342-344

[28] Bono F, Giliberto C, Mastrandrea C et al. Transverse sinus stenoses persist after normalization of the CSF pressure in IIH. Neurology 2005; 65: 1090-1093

[29] Juhász J, Lindner T, Jansen O et al. Changes in intracranial venous hemodynamics in a patient with idiopathic intracranial hypertension after lumbar puncture precedes therapeutic success. Journal of magnetic resonance imaging: JMRI 2018; 47: 286-288
[30] de Simone R, Ranieri A, Montella S et al. The role of dural sinus stenosis in idiopathic intracranial hypertension pathogenesis: the self-limiting venous collapse feedback-loop model. Panminerva medica 2014; 56: 201-209

[31] Bateman GA. Association between arterial inflow and venous outflow in idiopathic and secondary intracranial hypertension. Journal of clinical neuroscience: official journal of the Neurosurgical Society of Australasia 2006; 13: 550-556; discussion 557

[32] Juhász J, Lindner T, Riedel C et al. Quantitative Phase-Contrast MR Angiography to Measure Hemodynamic Changes in Idiopathic Intracranial Hypertension. AJNR. American journal of neuroradiology 2018; 39: 682686

[33] Bastin ME, Sinha S, Farrall AJ et al. Diffuse brain oedema in idiopathic intracranial hypertension: a quantitative magnetic resonance imaging study. Journal of neurology, neurosurgery, and psychiatry 2003; 74: 1693-1696

[34] Ireland B, Corbett J], Wallace RB. The search for causes of idiopathic intracranial hypertension. A preliminary case-control study. Archives of neurology 1990; 47: 315-320

[35] Hoffmann J, May A. Neues beim Pseudotumor cerebri (Idiopathische intrakranielle Hypertension). Akt Neurol 2017; 44: 466-475

[36] Giuseffi V, Wall M, Siegel PZ et al. Symptoms and disease associations in idiopathic intracranial hypertension (pseudotumor cerebri): a case-control study. Neurology 1991; 41: 239-244

[37] Kesler A, Goldhammer Y, Hadayer A et al. The outcome of pseudotumor cerebri induced by tetracycline therapy. Acta neurologica Scandinavica 2004; 110: 408-411

[38] Rohr A. Pseudotumor cerebri. Radiologie up2date 2008; 8: 183-199

[39] Rohr AC, Riedel C, Fruehauf M-C et al. MR imaging findings in patients with secondary intracranial hypertension. AJNR. American journal of neuroradiology 2011; 32: 1021-1029

[40] Friedman DI, Liu GT, Digre KB. Revised diagnostic criteria for the pseudotumor cerebri syndrome in adults and children. Neurology 2013; 81 : 1159-1165

[41] Salehi Ravesh M, Jensen-Kondering U, Juhasz J et al. Optimization of 3D phase contrast venography for the assessment of the cranio-cervical venous system at 1.5 T. Neuroradiology 2019; 61: 293-304

[42] Wall M. Update on idiopathic intracranial hypertension. Neurologic clinics 2017; 35: 45-57

[43] Rohr A, Bindeballe J, Riedel C et al. The entire dural sinus tree is compressed in patients with idiopathic intracranial hypertension: a longitudinal, volumetric magnetic resonance imaging study. Neuroradiology 2012; 54: 25-33

[44] Baryshnik DB, Farb RI. Changes in the appearance of venous sinuses after treatment of disordered intracranial pressure. Neurology 2004; 62: 1445-1446

[45] Rohr A, Reimann G, Alfke K et al. Pseudotumor cerebri - was ist normal? Normwerte für indirekte marker bei intrakranieller Hypertension. Fortschr Röntgenstr 2008; 180: 884-890

[46] Piper RJ, Kalyvas AV, Young AMH et al. Interventions for idiopathic intracranial hypertension. The Cochrane database of systematic reviews 2015; 8: CD003434

[47] Thenuwara K, Todd MM, Brian JE. Effect of mannitol and furosemide on plasma osmolality and brain water. Anesthesiology 2002; 96: 416-421

[48] Celebisoy N, Gökçay F, Sirin H et al. Treatment of idiopathic intracranial hypertension: topiramate vs acetazolamide, an open-label study. Acta neurologica Scandinavica 2007; 116: 322-327

[49] Mollan SP, Davies B, Silver NC et al. Idiopathic intracranial hypertension: consensus guidelines on management. Journal of neurology, neurosurgery, and psychiatry 2018; 89: 1088-1100 
[50] Berdahl JP, Fleischman D, Zaydlarova J et al. Body mass index has a linear relationship with cerebrospinal fluid pressure. Investigative ophthalmology \& visual science 2012; 53: 1422-1427

[51] Kupersmith MJ, Gamell L, Turbin R et al. Effects of weight loss on the course of idiopathic intracranial hypertension in women. Neurology 1998; 50: 1094-1098

[52] Bateman GA. Stenoses in idiopathic intracranial hypertension: to stent or not to stent? AJNR. American journal of neuroradiology 2008; 29: 215; author reply 215-216

[53] Teleb MS, Cziep ME, Issa M et al. Stenting and angioplasty for idiopathic intracranial hypertension: a case series with clinical, angiographic, ophthalmological, complication, and pressure reporting. Journal of neuroimaging: official journal of the American Society of Neuroimaging 2015; 25: 72-80
[54] Higgins JNP, Cousins C, Owler BK et al. Idiopathic intracranial hypertension: 12 cases treated by venous sinus stenting. Journal of neurology, neurosurgery, and psychiatry 2003; 74: 1662-1666

[55] Abubaker K, Ali Z, Raza K et al. Idiopathic intracranial hypertension: lumboperitoneal shunts versus ventriculoperitoneal shunts-case series and literature review. British journal of neurosurgery 2011; 25: 94-99

[56] Corbett J], Nerad JA, Tse DT et al. Results of optic nerve sheath fenestration for pseudotumor cerebri. The lateral orbitotomy approach. Archives of ophthalmology (Chicago, Ill.: 1960) 1988; 106: 1391-1397

[57] Handley JD, Baruah BP, Williams DM et al. Bariatric surgery as a treatment for idiopathic intracranial hypertension: a systematic review. Surgery for obesity and related diseases: official journal of the American Society for Bariatric Surgery 2015; 11: 1396-1403 